\title{
Cyclic voltammetry: A tool to quantify 2,4,6-trichloroanisole in aqueous samples from cork planks boiling industrial process
}

\author{
António M. Peres a,b,*, Patrícia Freitas ${ }^{\mathrm{c}}$, Luís G. Dias ${ }^{\mathrm{b}}$, Mara E.B.C. Sousa ${ }^{\mathrm{b}}$, Luís M. Castro ${ }^{\mathrm{c}, \mathrm{d}}$, \\ Ana C.A. Veloso ${ }^{\text {c,e }}$ \\ ${ }^{a}$ LSRE-Laboratory of Separation and Reaction Engineering-Associate Laboratory LSRE/LCM, Escola Superior Agrária, Instituto Politécnico de Bragança, \\ Campus Santa Apolónia, Apartado 1172, 5301-855 Bragança, Portugal

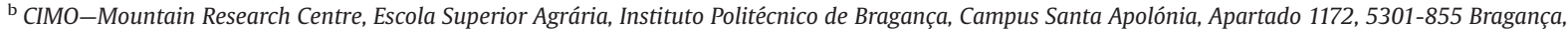 \\ Portugal \\ ' Instituto Politécnico de Coimbra, ISEC, DEQB, Rua Pedro Nunes, Quinta da Nora, 3030-199 Coimbra, Portugal \\ d GERSE-DCE/FST, Group on Environment, Reaction and Separation Engineering, Department of Chemical Engineering, Faculty of Sciences and Technology, \\ University of Coimbra, Rua Sílvio Lima, Pólo II, 3030-790 Coimbra, Portugal \\ e IBB, Institute for Biotechnology and Bioengineering, Center of Biological Engineering, University of Minho, Campus de Gualtar, 4710-057 Braga, Portugal
}

\section{A R T I C L E I N F O}

\section{Article history:}

Received 19 June 2013

Received in revised form

17 September 2013

Accepted 20 September 2013

Available online 25 September 2013

Keywords:

2,4,6-trichloroanisole

Cork

Cyclic voltammetry

Standard addition method

\begin{abstract}
A B S T R A C T
Chloroanisoles, namely 2,4,6-trichloroanisole, are pointed out as the primary responsible of the development of musty off-flavours in bottled wine, due to their migration from cork stoppers, which results in huge economical losses for wine industry. A prevention step is the detection of these compounds in cork planks before stoppers are produced. Mass spectrometry gas chromatography is the reference method used although it is far beyond economical possibilities of the majority of cork stoppers producers. In this work, a portable cyclic voltammetry approach was used to detect 2,4,6-trichloroanisole extracted from natural cork planks to the aqueous phase during the cork boiling industrial treatment process. Analyses were carried out under ambient conditions, in less than 15 min with a low use of solvent and without any sample pre-treatment. The proposed technique had detection $(0.31 \pm 0.01 \mathrm{ng} / \mathrm{L})$ and quantification $(0.95 \pm 0.05 \mathrm{ng} / \mathrm{L})$ limits lower than the human threshold detection level. For blank solutions, without 2,4,6-trichloroanisole addition, a concentration in the order of the quantification limit was estimated $(1.0 \pm 0.2 \mathrm{ng} / \mathrm{L})$, which confirms the satisfactory performance of the proposed methodology. For aqueous samples from the industrial cork planks boiling procedure, intra-day repeatabilities were lower than 3\%, respectively. Also, 2,4,6-trichloroanisole contents in the aqueous samples determined by this novel approach were in good agreement with those obtained by GC-MS (correlation coefficient equal to 0.98 ), confirming the satisfactory accuracy of the proposed methodology. So, since this novel approach is a fast, low-cost, portable and user-friendly method, it can be an alternative and helpful tool for in-situ industrial applications, allowing accurate detection of releasable 2,4,6-trichloroanisole in an earlier phase of cork stoppers production, which may allow implementing more effective cork treatments to reduce or avoid future 2,4,6-trichloroanisole contaminations of wine.
\end{abstract}

(c) 2013 Elsevier B.V. All rights reserved.

\section{Introduction}

Wine contamination with fungal aromas is a major problem for the wine industry, namely the organoleptic defect usually (and erroneously) designated as cork taint [1]. Although other sources of contamination exist $[1,2]$ cork is pointed out as its main cause,

\footnotetext{
* Corresponding author at: LSRE-Laboratory of Separation and Reaction Engineering-Associate Laboratory LSRE/LCM, Escola Superior Agrária, Instituto Politécnico de Bragança, Campus Santa Apolónia, Apartado 1172, 5301-855 Bragança, Portugal. Tel.: + 351 273303220; fax: +351 273325405.

E-mail address: peres@ipb.pt (A.M. Peres).
}

since cork stoppers would be the source of wine contamination by chloroanisoles, specially 2,4,6-trichloroanisole (2,4,6-TCA), that confers a very unpleasant fungal aroma to the wine even at concentrations of $2-4 \mathrm{ng} / \mathrm{L}$ [3]. Different detection (1.4-4.6 ng/L) and recognition thresholds $(4.2-10 \mathrm{ng} / \mathrm{L})$ have been reported [3]. The former can be defined as the minimum value of a sensory stimulus needed to give rise to a sensation and the latter as the minimum value of a sensory stimulus permitting identification of the sensation perceived [1]. However, other chemical compounds, like 2,4,6-tribromoanisole, 2-methoxy-3,5-dimethylpyrazine, geosmine, guaiacol, 1-octen-3-one, 1-octen-3-ol or 2-methyl-isoborneol, are also able to taint the wine with fungal off-odours [4,5]. 
2,4,6-TCA is a metabolite formed from the biomethylation of chlorophenol presented in contaminated environment, usually by filamentous fungi, growing on cork [6]. To prevent the contamination of bottled wine with 2,4,6-TCA, manufacturers monitor its level in cork stoppers using two approaches: quantification of 2,4,6-TCA in cork stoppers or in the water used during the boiling procedure of cork planks before cork stoppers production. The latter case, may allow increasing cork time treatments or implementing new cork treatments, and, specially, avoid the cross-contamination of cork processed by means of contaminated boiling water. In either case, solid-phase microextraction (SPME) followed by the quantification of 2,4,6-TCA using gas chromatographic (GC) analysis with mass spectrometric (MS) detection or electron capture detection (ECD) are the most common quality control methods used by cork stoppers manufactures and cellars [7]. Sample preparation step is required due to the complexity of the matrix (e.g., wine, boiling cork water, washing cork stoppers water, cork stoppers or cork planks) and the low 2,4,6-TCA concentration expected [8,9]. For example, Patil et al. [10] developed a simple, fast, efficient, precise and cheap sample preparation method, based on dispersive solid-phase extraction, for the determination of the 2,4,6-TCA residues in white and red wine, using GC-MS with a detection limit lower than $10 \mathrm{ng} / \mathrm{L}$. MárquezSillero et al. $[11,12]$ were able to quantify $2,4,6-$ TCA in wine samples using ionic liquid-based single-drop microextraction together with ion mobility spectrometry [11] or single-drop ionic liquid microextraction coupled with multicapillary column separation and ion mobility spectrometry detection [12], with limits of detection of 0.2 and $0.01 \mathrm{ng} / \mathrm{L}$, respectively. More recently, Karpas et al. [13] have used ion mobility spectrometry to detect $2,4,6$-TCA in wine, after preconcentration and pre-separation steps. The work carried out by Schmarr et al. [14] showed that solid-phase extraction followed by multidimensional GC-MS could be applied to detect trace levels ( $<1 \mathrm{ng} / \mathrm{L}$ ) of corky off-flavour compounds in wine samples, namely 2,4,6-TCA, well below olfactory thresholds reported for these analytes. Other pre-concentration approaches have been proposed: pervaporation [15], pressurised liquid extraction [16], supercritical fluid extraction [17], SPME [18-24], stir bar sorptive extraction [25,26], single drop microextraction [27], dispersive liquid-liquid microextraction $[28,29]$, ultrasound-assisted emulsification microextraction [30], microwave assisted extraction [31] and microwave assisted extraction combined with dispersive liquid-liquid microextraction [9]. Recently, other methodologies rather than GC-MS based techniques have been proposed to detect and quantify 2,4,6-TCA mostly in wine. Immunoanalytical techniques [32,33] were developed and applied allowing the detection of 2,4,6-TCA, although in ranges well above the human detection threshold for wine.

Regarding cork samples, fewer works have been published so far. Juanola et al. [34] quantified 2,4,6-TCA in cork stoppers (both spiked non-contaminated corks and naturally contaminated cork) using a GC-ECD apparatus, after solid phase microextraction. The proposed procedure allowed quantifying 2,4,6-TCA concentrations ranging from 0.08 and $105.01 \mu \mathrm{g} / \mathrm{kg}$. Nevertheless, the methodology used had high variability even when quantifying 2,4,6-TCA in control and spiked cork samples. Ezquerro et al. [35] developed an analytical method based on pressurised fluid extraction and GCMS to determine 2,4,6-TCA in three naturally-tainted cork stopper samples, obtaining relative standard deviation percentages (RSD\%) between $10 \%$ and $20 \%$. Riu et al. [36] proposed a method for quantifying chloroanisoles, including 2,4,6-TCA in cork using headspace solid-phase microextraction and GC-ECD. The method allow determining the total amount of these compounds in cork stoppers (e.g., natural, agglomerated and agglomerated with disks) with a quantification limit for 2,4,6-TCA of $8.6 \mu \mathrm{g} / \mathrm{kg}$, with good recoveries (between $90 \%$ and 106\%), repeatabilities (4\% $<$ RSD $<13 \%)$ and intermediate precision ( $5 \%<$ RSD $<14 \%$ ). Vlachos et al. [37] developed an instrumental method for 2,4,6-TCA analysis in cork stoppers, based on headspace SPME and GC coupled with an ECD. Although the method showed satisfactory linearity, repeatability (RSD\% equal to $5.72 \%$ ) and sensitivity, with limit of detection of $0.366 \mathrm{ng} / \mathrm{L}$, these authors identified several matrix effects causing significant bias to the quantitative analysis of 2,4,6-TCA in cork soak. Vestner et al. [31] developed a microwave assisted extraction method for the analysis of 2,4,6-TCA in cork stoppers using stable isotope dilution assay in combination with stir bar sorptive extraction followed by GC-MS detection in the soaks samples, with a detection limit of $0.5 \mathrm{ng} \mathrm{L}^{-1}$. Prat et al. [38] proposed a tool for sensory classification of cork stoppers based on the analysis of the volatile fraction of aqueous cork macerates, including 2,4,6-TCA, of tainted and non-tainted agglomerate cork stoppers by headspace SPME-GC. Olivella et al. [39] used GC-MS to quantify 2,4,6-TCA present in preconcentrated aqueous solution of cork soaks. Schmarr et al. [14] quantified the presence of trace levels of 2,4,6-TCA in cork soak samples using solid-phase extraction followed by multidimensional GC-MS. More recently, Slabizki and Schmarr [40] used a multidimensional GC-ECD to quantify corky off-flavour compounds at ultra trace level (low ng/L).

However, all these analytical methods are usually beyond the economic and technical possibilities of most cork producers, which are typically micro and small familiar enterprises, and are only applied to analyze a few samples of the final product [41]. So, finding a fast, simple and economic portable analytical method to quantify 2,4,6-TCA in aqueous solutions collected during cork planks industrial treatment, with a minimal sample preparation, which could be applied in-situ, is still a challenging task.

In the literature, some sensor based systems have also been proposed to quantify 2,4,6-TCA in cork samples. Moore et al. [32] developed a biosensor based on screen printed electrodes for the quantitative detection of 2,4,6-TCA using screen printed electrodes, with a limit of detection of $29 \mathrm{ng} / \mathrm{L}$ in buffer matrices, but failed to meet real sample analysis in wine. Electrochemical displacement immunosensors were proposed by Duarte et al. [33] for 2,4,6-TCA detection in buffer samples with high detection limits $(200 \mu \mathrm{g} / \mathrm{L})$. More recently, Varelas et al. [41] proposed a fast (3-5 min) and lowcost cellular biosensor to monitor low 2,4,6-TCA concentrations (1-12 ng/L), which was tested for assaying 2,4,6-TCA preparations in white wine and for 2,4,6-TCA extracted from cork soaks in white wine.

In this work, and based on the satisfactory preliminary results already obtained by the research team, for Acetonitrile (ACN)/water standard solutions [42], the potential use of cyclic voltammetry (CV) without any pre-treatment step, as a prevention tool, for quantifying $2,4,6$-TCA (in the range of the regulatory and human detection thresholds) present in real aqueous solutions obtained from a cork boiling industrial process, was evaluated. The performance of the $\mathrm{CV}$ method was assessed by comparing the results obtained with those determined by a reference GC-MS method, following the requirements of the ISO standard 20752:2007 [7].

\section{Materials and methods}

\subsection{Reagents}

All reagents were of analytical grade and used as purchased. Acetonitrile (ACN, from Labscan), with a minimum purity of $99.8 \%$, 2,4,6-Trichloroanisole (2,4,6-TCA) and tetrabutylammonium perchlorate (TBAP) were purchased to Aldrich and Fluka, respectively, both with a minimum purity of $99 \%$. Deionised water was obtained from a TGI pure water system. Sodium chloride, from Sigma-Aldrich, had a minimum purity of $99.8 \%$. Deuterated 2,4,6-TCA (2,4,6-TCA-d5), was 
purchased to Cambridge Isotope Laboratories, Inc., with a minimum purity of $98 \%$.

\subsection{Samples}

Twenty two real aqueous samples were collected according to the routine quality control procedure implemented at a Portuguese cork stopper industry, during 2012 (January, April, July and September). Samples were picked during the boiling process of cork planks carried out in the cork factory, which consist in aqueous solutions resulting from the immersion of cork planks in boiling water $\left(100{ }^{\circ} \mathrm{C}\right)$ during $60 \mathrm{~min}$. All samples were kept at $4{ }^{\circ} \mathrm{C}$ until use, inside amber glass bottles protected from light. The aqueous samples collected at cork industry were used as received, without any further treatment. Indeed, no concentration, extraction or filtration process was employed.

\subsection{Quantification of 2,4,6-trichloroanisole}

In this work, each sample of the aqueous phase collected from cork planks boiling process was divided and quantified in terms of 2,4,6-TCA by the reference GC-MS method and by the proposed CV methodology.

\subsubsection{GC-MS analysis}

In this work, the 2,4,6-TCA, present in the aqueous solutions from the cork planks boiling process, was quantified using a solidphase microextraction (SPME with a $100 \mu \mathrm{m}$ polydimethylsiloxane fiber) followed by gas chromatography (GC). A Thermo Trace GC Ultra Cromatograph with a TG-5MS column (5\% Phenyl Methylpolysiloxane capillary column) with a Thermo ISQ single quadrupole mass spectrometer (MS) detector was used. The analysis was performed accordingly to the methodology described in ISO 20752:2007 Standard [7] and in OIV's Resolution 296/2009 for determination of 2,4,6-TCA [43] in wine as well as that described by Riboulet et al. [44] for wine and cork stoppers macerates. For quantification purposes, the internal standard calibration method was chosen. A standard hydro-ethanolic $(12 \% \mathrm{v} / \mathrm{v})$ solution of 2,4,6-TCA-d5 was used as the internal standard. The overall calibration was carried out with 2,4,6-TCA standard solutions, with concentrations ranging from $0.5 \mathrm{ng} / \mathrm{L}$ to $50 \mathrm{ng} / \mathrm{L}$.

Aliquots of the aqueous solutions from the cork planks boiling process were transferred into test vials that had an open space volume of half of the total vial capacity to avoid any contact between the fiber and the liquid phase. Before closing the vials, $\mathrm{NaCl}$ was added, until saturation, to facilitate the extraction process and finally 2,4,6-TCA-d5 internal standard solution was also added. The fiber was inserted in vials open space for adsorption during $30 \mathrm{~min}$ at $40 \pm 2{ }^{\circ} \mathrm{C}$. Afterwards, the fiber was desorbed during $15 \mathrm{~min}$ at $260{ }^{\circ} \mathrm{C}$ in the GC injector. Helium was used as the carrier gas at a constant flow of $1 \mathrm{ml} / \mathrm{min}$. For quantification, the area of the chromatographic peak of 2,4,6-TCA was corrected considering the peak area of the internal standard. The detection was done in MS/MS mode, with detection of 3 ions and quantification through the most abundant ion, having as precursor ion and product ion the $m / z 217$ and 199 ions, respectively, for the 2,4,6TCA-d5, and the $m / z 212$ and 197 ions for the 2,4,6-TCA.

\subsubsection{Cyclic voltammetry analysis}

The experimental conditions for 2,4,6-TCA analysis were those already established by the research team [42], namely the relative volumetric proportion of ACN/water $(3: 2, \mathrm{v} / \mathrm{v})$ and the final TBAP concentration $(0.1 \mathrm{M})$, which was used as the supporting electrolyte since ammonium salts have been reported to increase maximum current intensity when using silver working electrodes [45], as well as the number of voltammogram scans (two), scan rate $(100 \mathrm{mV} / \mathrm{s})$ and analysis temperature (ambient temperature). The use of ACN/water as solvent was mainly due to solubility reasons of 2,4,6-TCA and TBAP, which are low soluble in water. Water was used as co-solvent since the samples collected from the cork plank boiling process are aqueous solutions. Moreover, it is known that with silver electrodes it is advantageous to use water as co-solvent since it increases the catalytic effects of silver [45]. The precision and accuracy of the proposed CV methodology were evaluated by means of the standard addition method using ACN/water solutions and ACN/aqueous sample solutions (both $3: 2 \mathrm{v} / \mathrm{v}$ ), with $0.1 \mathrm{M}$ TBAP, as well as the detection and quantification limits. Since 2,4,6-TCA standard solution is added to a fixed volume of ACN/ water or ACN/aqueous sample, 2,4,6-TCA quantification must take into account a dilution factor [46]. Finally, it should be stated that all CV experiments were carried out in a constant medium (namely, ACN/water or ACN/aqueous sample $(3: 2 \mathrm{v} / \mathrm{v})$ with $0.1 \mathrm{M}$ TBAP as the supporting electrolyte), for minimizing possible blank effects of different $A C N$ relative proportion amounts in the final aqueous solutions as well as differences in TBAP concentrations. Also, the use of an addition standard calibration method, which requires a new calibration for each sample, allowed overcoming or minimizing possible matrix interferences.

2.3.2.1. Equipment and measurements. A portable PotentiostatGalvanostat device (PG580, Uniscan) together with a silver working electrode (M295Ag, Radiometer), a platinum counter electrode (M241Pt, Radiometer) and an $\mathrm{Ag} / \mathrm{AgCl}$ double-junction reference electrode (M90-02, Orion), were used. The cylindrical working electrode ( $5 \mathrm{~mm}$ diameter, $5 \mathrm{~mm}$ length) used had a calculated geometric area of approximately $98 \mathrm{~mm}^{2}$. These electrodes were used throughout the entire study and carefully washed with deionised water, not requiring any preconditioning or pre-stabilizing step. The silver electrode was further and thoroughly cleaned with rough absorbent paper to obtain a clean surface, before an assay. In this work an Ag electrode was chosen since it is reported to have high electrocatalytic activity for halide organic compounds reduction, remarkable cage effect and a large hydrogen overvoltage [45,47].

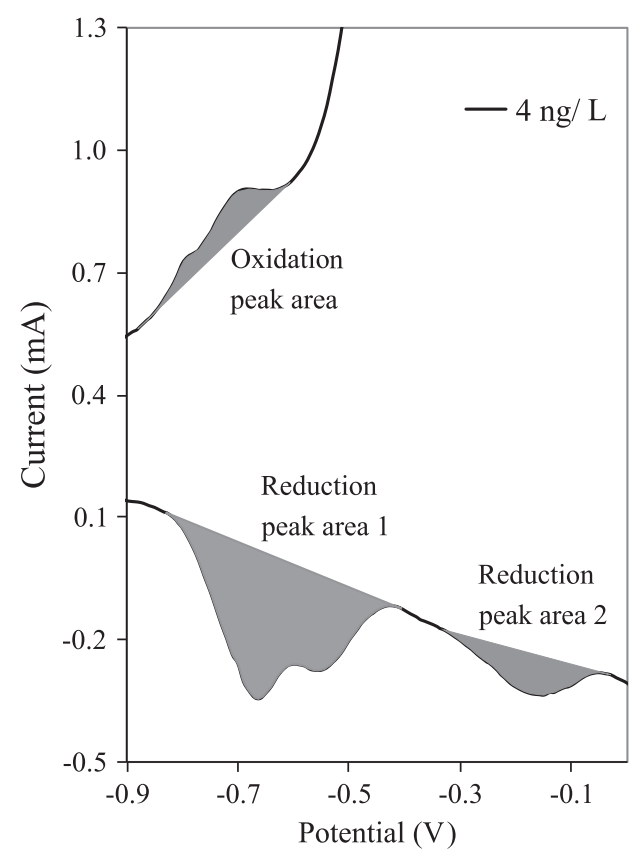

Fig. 1. Cyclic voltammogram reduction and oxidation peaks areas used to calculate the overall signal of 2,4,6-TCA in an ACN/aqueous solution. 
Signal acquisition was performed using the UiEChem v.1.34 software (Uniscan Instruments Ltd). Two cycles were performed being the cyclic voltammograms recorded from -2.0 to $1.6 \mathrm{~V}$, at a potential scan rate of $100 \mathrm{mV} / \mathrm{s}$ (Fig. 1), being only the second scan used for 2,4,6-TCA analysis. All the assays were made at ambient temperature.

2.3.2.2. Cyclic voltammogram background repeatability study. The repeatability of the cyclic voltammograms background was studied. Blank ACN/water solutions (3:2 v/v) with $0.1 \mathrm{M}$ TBAP were freshly prepared in three different days and analysed twice in each day. Intraand inter-days variabilities were evaluated by visually comparing the overlapping degree between the cyclic voltammograms recorded.

2.3.2.3. Identification of 2,4,6-TCA oxidation and reduction peaks. The identification of the oxidation and reduction peaks due to the presence of 2,4,6-TCA was carried out by comparing the cyclic voltammograms recorded in solutions with and without 2,4,6-TCA. The cyclic voltammogram of ACN/water solutions (3:2 v/v) containing TBAP $(0.1 \mathrm{M})$, which mimicked the final mixture obtained after diluting the aqueous samples collected during cork planks boiling process with $0.17 \mathrm{M}$ TBAP in ACN, were compared with those recorded after 2,4,6-TCA addition. This addition was accomplished by using a standard solution of 2,4,6-TCA in ACN/water (3:2 v/v) with $0.1 \mathrm{M}$ TBAP. The final solutions had 2,4,6-TCA concentrations within the ranges of the human detection threshold (between 1 and $5 \mathrm{ng} / \mathrm{L}$ ).

\subsubsection{Calibration method - detection and quantification limits.} Standard solutions (approximately, $200 \mathrm{ng} / \mathrm{L}$ ) were prepared by dissolving pre-weighted known amounts of 2,4,6-TCA in ACN/water solutions $(3: 2 \mathrm{v} / \mathrm{v}$ ) with $0.1 \mathrm{M}$ TBAP, followed by appropriate dilutions, in order that the final concentration of 2,4,6-TCA, after each standard addition $(4 \times 150 \mu \mathrm{L})$ to a pre-defined volume $(25 \mathrm{~mL})$ of $\mathrm{ACN} /$ water or aqueous sample solution, varied between 1 and $6 \mathrm{ng} / \mathrm{L}$. To minimize interferences in the sample matrix, the total volume of the added standard solution was always lower than $3 \%$ of the total volume. For each assay, two scans were performed, corresponding to 2 min of analysis. Calibration curves were obtained using the standard addition method considering the appropriate dilution factor [46]. Detection (LOD) and quantification (LOQ) limits were also calculated using the oxidation and reduction profiles recorded in the region of -0.9 to $0 \mathrm{~V}$, based on the linear relationship obtained between the current amplitude (considering the sum of both reduction and oxidation peaks, as shown in Fig. 1) corrected after subtracting that of the blank solution (0.1 M TBAP in ACN/water solution, 3:2 v/v) and the added 2,4,6-TCA concentrations. An approach similar to that usually adopted in chromatographic analysis was selected. Indeed, since irreversible cyclic voltammograms are expected [42], the sum of both reduction peak areas and oxidation peak area was calculated using the drop perpendicular method with an interpolated tangent baseline, to facilitate computation and retaining the relevant information from each signal profile, as it is shown in Fig. 1, for a ACN/water solution added with 2,4,6-TCA (final concentration of 4 $\mathrm{ng} / \mathrm{L}$ ). The advantage of the simultaneous use of extracted features from both reduction and oxidation CV profiles has been described recently [48]. The LOD and LOQ were determined from the parameters of the calibration curves established, being defined as 3.3 and 10 times the value of the intercept error divided by the slope, respectively $[49,50]$. Moreover, the standard addition method was applied each time to calculate the concentration of 2,4,6-TCA in the blank solution ( $0.1 \mathrm{M}$ of TBAP in ACN/water mixture, 3:2 v/v), which should be zero, from a theoretical point of view, since it was not contaminated with 2,4,6-TCA.

2.3.2.5. Sample analysis - precision and accuracy of cyclic voltammetry method. For evaluating the CV method precision, aqueous samples collected at the cork stoppers industry were used after being diluted with ACN containing $0.17 \mathrm{M}$ TBAP in order to obtain a volumetric proportion of 3:2 and a final solution with 0.1 M TBAP. The 2,4,6-TCA concentrations, before and after standard solution addition, were calculated using a similar procedure as that described in the previous section for ACN/water solutions but taking into account the standard addition calibration method with a volume correction due to the dilution factor [46]. So, a linear relationship was established between the total current amplitude (considering the sum of both reduction and oxidation peaks, as shown in Fig. 1) multiplied by the final volume after each addition of the standard solution and the total added volume of the standard 2,4,6-TCA in ACN/water with $0.1 \mathrm{M}$ of TBAP. Then, using the regression line parameters (slope and intercept values) and the intercept value with the abscissa axis, the 2,4,6-TCA concentration in each aqueous sample of the cork plank boiling process was calculated [46]. So, for intra-day repeatability evaluation, three aqueous samples with low, middle and high 2,4,6-TCA concentrations (based on GC-MS results) were selected. Each sample, after dilution step, was analysed in triplicate in the same day under the working voltammetric conditions. Intra-day variability was assessed by calculating the RSD\%.

The accuracy of the proposed CV method was studied using aqueous samples from the cork planks boiling process. A validation process was carried out to test the acceptance of the CV method as an alternative methodology for 2,4,6-TCA quantification in real aqueous samples collected from the boiling procedure of cork planks used in cork stoppers industry. So, a comparison between the 2,4,6-TCA concentrations estimated by the CV method with those obtained by GC-MS, established as the reference procedure $[7,43,44]$, which were considered the real concentration values, was carried out, by testing, from a statistical point of view, if the slope and the intercept values could be considered equal to the theoretical expected ones (one and zero, respectively) [51,52].

\section{Results and discussion}

\subsection{Cyclic voltammograms background repeatability}

The repeatability of the cyclic voltammograms background was evaluated by visualizing (Fig. 2) intra- and inter-days variability of the voltammograms recorded for blank solutions of ACN/water $(3: 2 \mathrm{v} / \mathrm{v})$ with $0.1 \mathrm{M}$ TBAP. As can be inferred from Fig. 2, the 6 voltammograms recorded (in 3 different days, 2 times each day) show a satisfactory overlapping degree indicating negligible background variation, implying a satisfactory background repeatability.

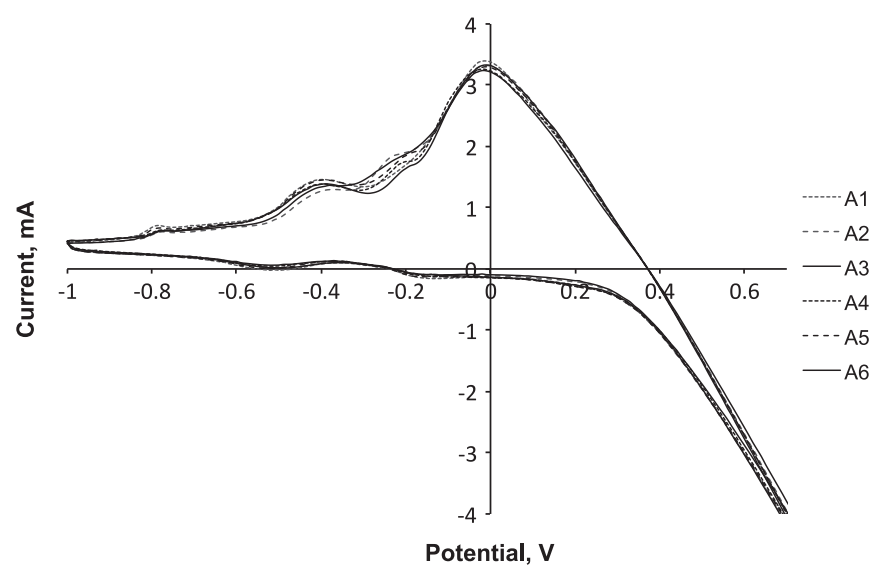

Fig. 2. Background repeatability of $\mathrm{CV}$ profiles of blank solutions of $\mathrm{ACN} /$ water $(3: 2 \mathrm{v} / \mathrm{v})$ with $0.1 \mathrm{M}$ TBAP. 


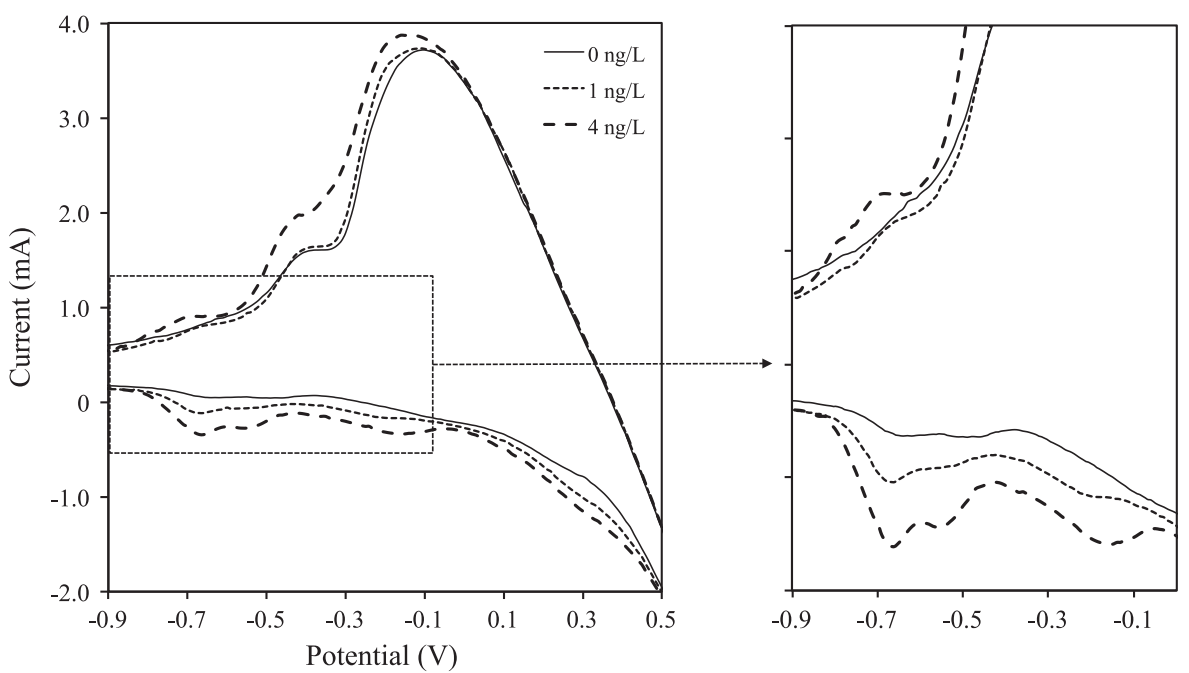

Fig. 3. $\mathrm{CV}$ profiles for $\mathrm{ACN} /$ water mixtures ( $3: 2 \mathrm{v} / \mathrm{v}$ with $0.1 \mathrm{M}$ of TBAP) without $(0 \mathrm{ng} / \mathrm{L})$ and with $2,4,6-\mathrm{TCA}$ addition $(1 \mathrm{and} 4 \mathrm{ng} / \mathrm{L})$.

The absence of appreciable variations may also allow inferring that, the eventual release of chloride ions from the reference electrode during each analysis, is not relevant or at least is constant between assays, which could be explained by use of a constant medium and operating conditions the study, and may be overcome by the standard addition calibration method chosen.

\subsection{Oxidation and reduction peaks identification of 2,4,6-TCA}

The voltammetric assays were performed in ACN/water solution, with a silver working electrode under experimental oxidative conditions. During the experiments it was observed the appearance of a thin black powder on the surface of the silver electrode, which could be attributed to the formation of silver oxide. However, at a certain extent, the formation of a silver oxide could be advantageous since it may improve silver catalytic activity [53]. Although this was a concern, it did not show a negative influence on the detection and quantification of 2,4,6-TCA, being always observed an incremental of the voltammetric signal recorded after each addition of the standard solution, without any evidence of signal saturation, implying that the catalytic activity of the Ag electrode was not greatly affected.

The oxidation and reduction peaks of 2,4,6-TCA were identified by comparing the voltammograms recorded in solutions with and without this compound. Fig. 3 shows a comparison between the $\mathrm{CV}$ profiles recorded between -2.0 and $1.4 \mathrm{~V}$ for $\mathrm{ACN} /$ water mixtures (3:2 v/v with $0.1 \mathrm{M}$ of TBAP) with or not 2,4,6-TCA additions.

The recorded voltammograms showed that only in the negative voltage region $(-0.9$ to $0 \mathrm{~V})$ there are significant differences between them, indicating that the presence of 2,4,6-TCA can be detected in this region, mainly in the reduction profile. In fact, oxidation and reduction peaks appear with the addition of 2,4,6TCA and increase with its concentration.

\subsection{Calibration method - detection and quantification limits}

Using the standard addition method, a linear relationship was obtained between the total oxidation and reduction current incremental amplitudes (oxidation peak area+reduction peak area 1 +reduction peak area 2 , according to Fig. 1 ), after blank signal area subtraction, and 2,4,6-TCA concentrations ( $R$ greater than 0.990 ) for ACN/water mixtures. An example of the calibration curve is given in Fig. 4, together with the respective linear parameters (slope and intercept values). The detection and quantification limits obtained were of $0.31 \pm 0.01 \mathrm{ng} / \mathrm{L}$ and

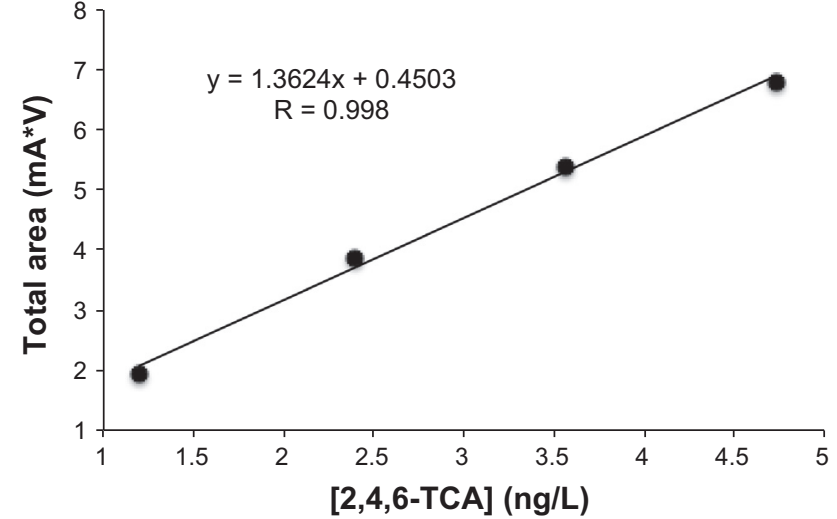

Fig. 4. Typical standard addition calibration curve obtained and used to calculate theoretical 2,4,6-TCA detection and quantification limits of the CV proposed methodology.

$0.95 \pm 0.05 \mathrm{ng} / \mathrm{L}$, respectively, which is a major advance compared with the previous results reported by our team [42]. Moreover, these limits are within both detection and recognition thresholds for 2,4,6-TCA [3], which confirms the feasibility of the proposed method to quantify 2,4,6-TCA. However, these limits are slightly higher than those reported using GC-MS $[12,14]$ or of the same order of magnitude [10] and similar to those obtained with biosensors [32,33], in wine analysis. Furthermore, they are similar to those reported in cork stoppers analysis [31,37] using GC-MS or using a biosensor [41].

The standard addition method was also applied to calculate the concentration of 2,4,6-TCA in the blank solution (0.1 M of TBAP in ACN/water solution, $3: 2 \mathrm{v} / \mathrm{v}$ ). An average concentration of $1.0 \pm 0.2 \mathrm{ng} / \mathrm{L}$ was obtained. Although a zero concentration was envisaged, since the solution was not contaminated with 2,4,6TCA, it should be emphasized that the estimated concentration of the blank is similar to the quantification limit of the CV method, possibly due to experimental errors.

\subsection{Sample analysis - precision and accuracy of CV method}

The concentrations of 2,4,6-TCA extracted from the cork planks to the aqueous phase of the industrial samples studied were quantified by GC-MS according to the reference methodology $[7,43,44]$. For the 22 samples analysed, in one sample the 2,4,6-TCA was not detected 


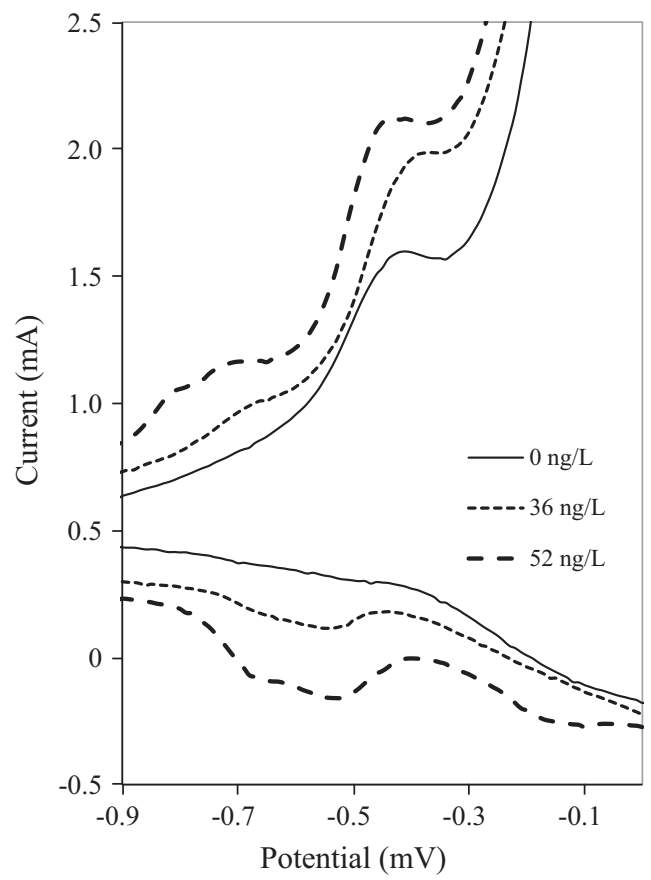

Fig. 5. Voltammograms of three ACN/aqueous real sample solution (from cork planks boiling treatment) containing different 2,4,6-TCA concentrations according to GC-MS analysis: 0,36 and $52 \mathrm{ng} / \mathrm{L}$.

and for the others, the concentrations ranged between 7.5 and $61.5 \mathrm{ng} / \mathrm{L}$. Fig. 5 shows an example of the voltammograms recorded for three samples (ACN/aqueous sample solution, 3:2 v/v with $0.1 \mathrm{M}$ of TBAP), in the potential region of -0.9 to $0 \mathrm{~V}$, with $2,4,6-\mathrm{TCA}$ concentrations obtained from GC-MS analysis: 0, 36 and $52 \mathrm{ng} / \mathrm{L}$. Similarly to the assays with ACN/water solutions, there are also significant differences between the voltammograms recorded for real aqueous sample solutions with 3 different levels of 2,4,6-TCA concentrations. This observation could be used, from a qualitative point of view, to rapidly infer, by visualizing the voltammographic profiles, if a sample was or not contaminated with 2,4,6-TCA, even for a non skilled technician. Moreover, it can also be inferred from Fig. 5 that an increase of 2,4,6-TCA concentration results in an increase of the oxidation and reduction signal in the referred potential range. These results demonstrate that the proposed $\mathrm{CV}$ method can be used as a tool for monitoring levels of 2,4,6-TCA in cork washing solutions.

The CV method precision was evaluated, through the intra-day repeatability, analysing three samples with 2,4,6-TCA concentrations of 7.5, 17.5 and $31.0 \mathrm{ng} / \mathrm{L}$, according to GC-MS analysis. The RSD\% values were equal to $0.3 \%, 2.0 \%$ and $3.0 \%$, respectively. These results are lower than $5 \%$ indicating a satisfactory overall precision [49]. Furthermore, they are lower or of the same order of magnitude of those reported in the literature for GC-MS analysis of cork samples $[14,31,36,37,39]$.

The accuracy of the proposed method was further evaluated by comparing the 2,4,6-TCA concentrations of the aqueous sample solutions from the cork planks boiling procedure, calculated using voltammetric data together with the standard addition calibration method (typical calibration curve shown in Fig. 6, being $R>0.990$ for all sample analysis), with those determined by the GC-MS considered as the reference method. For this purpose a linear regression model (LRM) was established, which is shown in Fig. 7, together with the confidence intervals for the estimation model and prediction at a significance level of $5 \%$. The slope and intercept values, as well the respective confidence intervals at a confidence level of 95\%, are shown in Table 1 . These results support

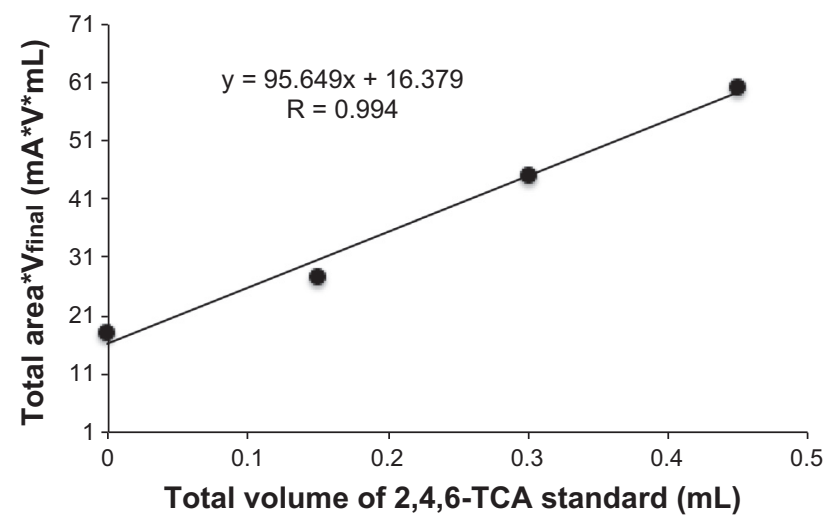

Fig. 6. Typical standard addition calibration curve established to calculate 2,4,6TCA concentrations in aqueous samples from the cork plank industrial boiling process, based on the CV proposed methodology.

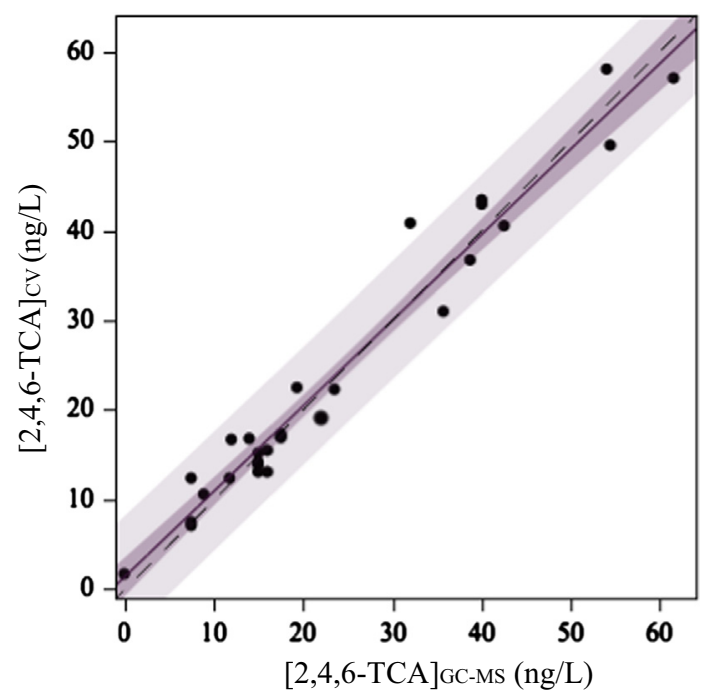

Fig. 7. Concentrations of 2,4,6-TCA in real aqueous samples from cork planks boiling treatment, estimated by the proposed CV method versus measured by GC-MS considered as the reference method.

Table 1

Parameters of the linear regression model and their respective confidence intervals at $5 \%$ significance level.

\begin{tabular}{lcl}
\hline LRM & Values & Confidence interval $^{\mathrm{a}}$ \\
\hline Slope & $0.96 \pm 0.04$ & {$[0.88 ; 1.03]$} \\
Intercept $(\mathrm{ng} / \mathrm{L})$ & $1.3 \pm 1.0$ & {$[-0.84 ; 3.46]$} \\
\hline
\end{tabular}

a $t$-test at a $5 \%$ significance level.

satisfactory accuracy of the proposed method since the theoretical slope (value equal to 1 , represented as a dashed line in Fig. 7) is equivalent to that obtained from the experimental data (full line in Fig. 7). In fact, from a statistical point of view, the slope and intercept values of the LRM obtained can be considered equal to the theoretical expected ones, since the respective confidence intervals contain the one and zero values [51,52].

\section{Conclusions}

The satisfactory overall results obtained in this study, regarding the quantification of 2,4,6-TCA in real aqueous samples from the boiling procedure used at industrial level for cork planks 
treatment, before cork is used to manufacture cork stoppers, support the belief that the proposed CV method can be applied as practical quality control tool. This approach may allow reducing the number of samples that must be controlled by GC-MS reference method, consequently the cost of the control process. Also, since CV equipment is portable, fast, low-cost and does not require a skilled technician, it can be an helpful tool for in-situ industrial applications, particularly on the continuous control of the water quality in terms of 2,4,6-TCA, during the cork plank boiling process, which is fundamental to identify contaminated cork planks and to prevent the cross contamination of other cork lots. The proposed methodology is an accurate and effective methodology to quantify 2,4,6-TCA, which can be applied in an early treatment step of cork within the industrial cork stoppers production line, allowing implementing more effective cork treatments to reduce or avoid future 2,4,6-TCA contaminations of wine.

\section{Acknowledgments}

This work was partially supported by project PEst-C/EQB/ LA0020/2011, financed by FEDER through COMPETE - Programa Operacional Factores de Competitividade and by FCT - Fundação para a Ciência e a Tecnologia (Portugal).

\section{References}

[1] M.A. Sefton, R.F. Simpson, Aust. J. Grape Wine R. 11 (2005) 226-230.

[2] P. Chatonnet, S. Bonnet, S. Boutou, M.D. Labadie, J. Agric. Food Chem. 52 (2004) $1255-1262$.

[3] V. Mazzoleni, L. Maggi, Food Res. Int. 40 (2007) 694-699.

[4] R.F. Simpson, D.L. Capone, M.A. Sefton, J. Agric. Food Chem. 52 (2004) 5425-5430.

[5] M. Riu, M. Mestres, O. Busto, J. Guasch, J. Chromatogr. A 977 (2002) 1-8.

[6] JJ.R. Coque, E.R. Pérez, M. Goswami, R.F. Martínez, S.C. García, M.L.A. Rodríguez J.F.M. Martín, Wine Contamination by Haloanisoles: Towards the Development of Biotechnological Strategies to Remove Chloroanisoles from Cork Stoppers, in: J.J. R. Coque, J.F.M. Martín (Eds.), INBIOTEC, APCOR, Azuré Impresión y Comunicación, S.L., Spain, 2006, pp. 1-66.

[7] Cork stoppers-Determination of releasable 2,4,6-trichloroanisol (TCA), ISO 20752:2007, International Standard Organization, Switzerland, Geneva, 2007.

[8] A.R. Fontana, Trend Anal. Chem. 37 (2012) 135-147.

[9] C. Pizarro, C. Sáenz-González, N. Pérez-del-Notario, J.M. González-Sáiz, Food Chem. 132 (2012) 2202-2210.

[10] S.H. Patil, K. Banerjee, S.C. Utture, A.R. Fontana, J.C. Altamirano, D.P. Oulkar, S.S. Wagh, S. Dasgupta, S.B. Patil, M.R. Jadhav, B.R. Ugare, P.G. Adsule, M.B. Deshmukh, Food Chem. 124 (2011) 1734-1740.

[11] I. Márquez-Sillero, E. Aguilera-Herrador, S. Cárdenas, M. Valcárcel, Anal. Chim. Acta 702 (2011) 199-204.

[12] I. Márquez-Sillero, S. Cárdenas, M. Valcárcel, J. Chromatogr. A 1218 (2011) $7574-7580$.

[13] Z. Karpas, A.V. Guamán, D. Calvo, A. Pardo, S. Marco, Talanta 93 (2012) 200-205.

[14] H.G. Schmarr, S. Koschinski, W. Sang, P. Slabizki, J. Chromatogr. A 1226 (2012) 96-102.

[15] J.L. Gómez-Ariza, T. García-Barrera, F. Lorenzo, J. Chromatogr. A 1049 (2004) $147-153$.

[16] J.L. Gómez-Ariza, T. García-Barrera, F. Lorenzo, A.Gustavo González, Anal. Chim. Acta 540 (2005) 17-24.
[17] M.K. Taylor, T.M. Young, C.E. Butzke, S.E. Ebeler, J. Agric. Food Chem. 48 (2000) $2208-2211$.

[18] G.J. Soleas, J. Yan, T. Seaver, D.M. Goldberg, J Agric. Food Chem. 50 (2002) 1032-1039.

[19] A. Martínez-Uruñuela, J.M. González-Sáiz, C. Pizarro, J. Chromatogr. A 1056 (2004) 49-56.

[20] A. Martínez-Uruñuela, J.M. González-Sáiz, C. Pizarro, J. Chromatogr. A 1089 (2005) 31-38.

[21] S. Insa, E. Anticó, V. Ferreira, J. Chromatogr. A 1089 (2005) 235-242.

[22] C. Pizarro, N. Pérez-del-Notario, J.M. González-Sáiz, J. Chromatogr. A 1143 (2007) 26-35.

[23] C. Pizarro, N. Pérez-del-Notario, J.M. González-Sáiz, J. Chromatogr. A 1149 (2007) 138-144

[24] N. Campillo, R. Peñalver, M. Hernández-Córdoba, J. Chromatogr. A 1210 (2008) 222-228.

[25] Y. Hayasaka, K. MacNamara, G.A. Baldock, R.L. Taylor, A.P. Pollnitz, Anal. Bioanal. Chem. 375 (2003) 948-955.

[26] J.T. Huang, L. Alquier, J.P. Kaisa, G. Reed, T. Gilmor, G. Vasm, J. Chromatogr. A 1262 (2012) 196-204.

[27] E. Martendal, D. Budziak, E. Carasek, J. Chromatogr. A 1148 (2007) 131-136.

[28] N. Campillo, P. Viñas, J.I. Cacho, R. Peñalver, M. Hernández-Córdoba, J. Chromatogr. A 1217 (2010) 7323-7330.

[29] C. Pizarro, C. Sáenz-González, N. Perez-del-Notario, J.M. González-Sáiz J. Chromatogr. A 1217 (2010) 7630-7637.

[30] J. Regueiro, M. Llompart, C. Garcia-Jares, J.C. Garcia-Monteagudo, R. Cela, J. Chromatogr. A 1190 (2008) 27-38.

[31] J. Vestner, S. Fritsch, D. Rauhut, Anal. Chim. Acta 660 (2010) 76-80.

[32] E. Moore, M. Pravda, G.G. Guilbault, Anal. Chim. Acta 484 (2003) 15-24.

[33] M.V. Duarte, P. Lozano-Sanchez, I. Katakis, Biosens. Bioelectron. 24 (2009) 2205-2210.

[34] R. Juanola, L. Guerrero, D. Subirà, V. Salvadó, S. Insa, J.A.G. Regueiro, E. Anticó, Anal. Chim. Acta 513 (2004) 291-297.

[35] Ó. Exquerro, Á. Garrido-López, M.T. Tena, J. Chromatogr. A 1102 (2006) 18-24.

[36] M. Riu, M. Mestres, O. Busto, J. Guasch, J. Chromatogr. A 1107 (2006) 240-247.

[37] P. Vlachos, A. Kampioti, M. Kornaros, G. Lyberatos, Food Chem. 105 (2007) 681-690.

[38] C. Prat, E. Besalú, L. Bañeras, E. Anticó, Food Chem. 126 (2011) 1978-1984.

[39] M.À. Olivella, J. Caixach, C. Planas, A. Oliveras, P. Jové, Chemosphere 86 (2012) 754-758.

[40] P. Slabizki, H.G. Schmarr, J. Chromatogr. A 1271 (2013) 181-184.

[41] V. Varelas, N. Sanvicens, M. Pilar-Marco, S. Kintzios, Talanta 84 (2011) 936-940.

[42] P. Freitas, L.G. Dias, A.M. Peres, L.M. Castro, A.C.A. Veloso, Procedia Eng. 47 (2012) 1125-1128

[43] Determination of releasable 2,4,6-trichloroanisole in wine by cork stoppers (Resolution OIV-Oeno 296/2009), Reference OIV-MA-AS315-16, in Compendium of International Analysis of Methods, vol. 2, International Organisation of Vine and Wine, France, Paris, 2012 pp. 1-8. 〈http://www.gie.uchile.cl/pdf/ GIE_legislacion/Metodos\%20Analisis_Vol.2.pdf).

[44] J.M. Riboulet, L.A.R. Alves, N. Urreizti, Ciência Téc. Vitiv. 17 (2002) 61-71.

[45] S.B. Rondinini, P.R. Musiini, F. Crippa, G. Sello, Electrochem. Commun. 2 (2000) 491-496.

[46] D.C. Harris, in: C. Bleyer (Ed.), Quantitative Chemical AnalysisWH Freeman and Company, USA, 2007, pp. 80-98.

[47] A.A. Peverly, J.A. Karty, D.G. Peters, J. Electroanal. Chem. 692 (2013) 66-71.

[48] J.M. Gutiérrez, Z. Haddi, A. Amari, B. Bouchikhi, A. Mimendia, X. Cetó, M. de Valle, Sens. Actuat. B 177 (2013) 989-996.

[49] J. Ermer, in: J. Ermer, J.H.McB. Miller (Eds.), Method Validation in Pharmaceutical Analysis. A Guide to Best Practice, Wiley-VCH Verlag GmbH \& Co. KGaA, Weinheim, 2005, pp. 21-101.

[50] L.R. Snyder, J.J. Kirkland, J.W. Dolan (Eds.), Introduction to Modern Liquid Chromatography, John Wiley \& Sons, Inc., Hoboken, New Jersey, USA, 2010.

[51] B. Roig, O. Thomas, Anal. Chim. Acta 477 (2003) 325-329.

[52] B. Roig, O. Thomas, Carbohydr. Res. 338 (2003) 79-83.

[53] Y.H. Xu, H. Zhang, C.P. Chu, C.A. Ma, J. Electroanal. Chem. 664 (2012) 39-45. 